\title{
THE PUZZLE OF ALBANIAN PO
}

\author{
BRIAN D. JOSEPH \\ The Ohio State University
}

\section{[1] PRELIMINARIES}

Albanian has an aspectual marker po that is used in marking progressive (continuative) aspect; it is described in grammars, e.g. in Newmark et al. $(1982,36)$, as denoting "a momentary action in progress". It occurs in the present with present tense forms, as in (1a) and also in the past, with the imperfect tense, as in (1b):

(1) a. Agimi po këndon 'Agim is singing'

b. Agimi po këndonte 'Agim was singing'

The value of po becomes clear when a sentence like (1a) is contrasted with a simple present tense without po that then denotes a general state, as in (2):

(2) Agimi këndon 'Agim sings' (habitually, i.e. 'is a singer')

It should be noted that there is an alternative way of expressing progressivity, described as follows by Newmark et al. $(1982,36)$ : "an action already in progress [can be] constructed with the verb jam ['be'] in the present or imperfect followed by a gerundive introduced by duke" and exemplified by (3):
a. I huaji
ishte duke kaluar kafshën
the stranger-NOM was-3SG PROG move-PPL animal-ACC.DEF
'The stranger was moving the beast'
b. Agimi është duke kënduar 'Agim is singing' (cf. (1a))

Although from these descriptions there is no reason to doubt that po is a progressive marker, there is some further independent supporting evidence. Newmark et al. $(1982,66)$ note that "verbs which designate actions or states that normally characterize the subject for an indefinite time are rarely, if ever, accompanied by... po", and this includes the verbs dua 'want' and di 'know', which do not happily occur in progressive forms in other languages, such as standard English. Thus on crosslinguistic grounds, the progressive nature of sentences with this verbal modifier po seems clear.

Still, there is more to be said. Thus, I offer here a fuller consideration of the nature of po, both as to its function and as to its origin. I argue that to fully understand how po functions in Albanian, or more accurately, how it came to function 
as it does, one needs to examine this form from a Balkan, an Indo-European, and a cross-linguistic perspective, as aspects of all three ways of placing Albanian into a larger linguistic context contribute towards an insightful account of po. This investigation thus leads to a consideration of the etymology of the form and how it developed within Albanian and in relation to other phenomena in neighboring languages.

of particular interest is the fact that even though there are numerous striking parallels between Albanian and other languages in the Balkans, e.g. Greek and Romanian (and similar facts can be found for Slavic), with regard to the structuring of the "verbal complex", i.e. the string of elements that occur with the verb in the marking of negation, tense, mood, voice, and argument structure, nonetheless po stands out as unusual in certain respects. The parallels in question are illustrated by the sentences in (4) and (5), from Albanian, dialectal Greek, and Daco-Romanian, respectively; this exercise could be extended with data from other Balkan languages, including Macedonian, Bulgarian, and Romani, though the examples in (4) and (5) suffice to make the point that the languages match up morphemic-slot-by-morphemic-slot with regard to various preverbal elements that modify the verb in some way. Structurally, therefore, even if the content of the particular morphemes serving as exponents of the relevant categories differs for each language, the slots are the same and thus the verbal complexes converge in terms of their form:
a. s' do të j a- jep (Albanian)
NEG FUT SUBJVE him-IO it-Do give-1SG
b. ðe $\theta \mathrm{e}$ na tu to đóso (dialectal Greek)
NEG FUT SUBJVE him-IO it-Do give-1sG
c. nu 0 să i $\quad-1$ dau (Daco-Romanian)
NEG FUT SUBJVE him-IO it-Do give-1SG
'I will not give it to him'

Moreover, "convergence" is precisely the right characterization for the facts in (4) and (5), since the means by which these modifying categories were realized in earlier stages of these languages was quite different; Ancient Greek, for instance, expressed future tense via a suffix on the verb stem, and the placement of weak object pronouns (treated here as markers of argument structure) operated within the do- 
main of the clause and was not bound to the verb as it is in the modern language.

What is interesting about Albanian po is that despite such cross-language parallelism in the verbal complex, this Albanian element is unique among the Balkan languages. That is, no other language shows a (more or less) free preverbal form that marks aspect and specifically a type of imperfectivity (in the sense of signaling an on-going event), that is, progressivity; Slavic, for instance, generally uses bound preverbs and stem-forming suffixes to mark different aspects, while Greek uses stem-forming suffixes, and Romanian does not formally distinguish aspect at all. ${ }^{1}$

\section{[2] Distribution Within ALBANIAN}

There are two relevant dimensions to the matter of the distribution within Albanian of po. First, there is the question of how it is represented lexically and functionally, since within Albanian, there is actually a wide range of meanings and thus functions associated with the form [po]. Without taking a stand on whether they are all the "same" element synchronically, a vexed issue for any language when there are homophonic forms serving distinct functions, ${ }^{2}$ we can discern the following uses, based on the characterizations given in Newmark $(1998,680)$; the illustrative meanings given follow Newmark:

(6) a. Particle:

- affirmative particle: 'yes; indeed'

- confirmative tag in questions: 'is that right?'

- confirmative identifier: 'exactly; precisely; the very'

- indicator of momentaneous (on-going) activity: 'be VERB-ing'

b. Interjection:

-'oh say! Say! But say!'

[1] Albanian, of course, offers duke (and dialect variants) as another instance of a more or less free preverbal form marking progressivity, though with duke, one has to factor in the need for a co-occurring participle, so that duke by itself does not mark aspect. It can be noted too that in modern Tsakonian Greek, there is a direct continuation of the Hellenistic Greek 'be' + participle construction, which, though signaling a simple present in New Testament Greek, presumably originated with a progressive sense, that is, 'I am (one-who-is-in-astate-of) seeing' (see, e.g., Decker 2007). The Tsakonian formation continues the simple present meaning, with no hint of progressivity, despite the periphrastic origin (so that emi oru, from earlier cỉul ó $\rho \omega ́ v$, means not 'I-am seeing', but rather simply 'I see'). Thus even though aspect is marked in many Balkan languages, po is unlike its functional counterparts.

[2] One can compare the question of whether all the forms to in English (leaving aside two and too!), namely the prepositional to, the infinitival to, the word-formative to (as in today), and so on, constitute manifestations of one and the same element. It is not easy to give a definitive answer here. For what it is worth, Newmark $(1998$, s.v.) lists them all in one dictionary entry but that could conceivably be merely a space-saving move (which dictionaries might engage in out of economic motivation), and not something based on an analytic judgment. 


\section{c. Conjunction: \\ - 'but' \\ - in conditional clauses: 'if; if only'}

Second, there is the issue of the dialect distribution of $p o$, focusing attention on the aspectual verbal progressivity function. It turns out that this particular po occurs in both Tosk (southern) and Geg (northern) Albanian, a fact that suggests strongly that it presumably is old within Albanian. Still, though represented in Tosk generally, as part of the standard language (gjuha standarde) for instance, progressive po is not found in outlying Tosk dialects, being absent from Arvanitika (in Greece) and Arbëresh (in southern Italy), where forms of duke (tuke, tue) occur with participials in progressives instead (a construction that is also an option in the standard language - see (2) above).

This distribution raises some questions about what the proto-Albanian status of po is, and thus invites an examination of the etymology of po, since the determination of the etymological starting point for po, in any or all of its uses, can in principle have an illuminating effect on our understanding of the paths of development po took and even on its synchronic behavior. As becomes clear in the next section, however, there is little in the way of definitive etymological light to be shed on po. Nonetheless, the investigation does yield some interesting and useful insights into the development of $p o$.

\section{[3] ETYMOLOGY}

There is a seemingly obvious external source for an aspectual marker in a Balkan language with the shape $p o,{ }^{3}$ namely the Slavic aspectual prefix po. However, at first glance, this presents a rather difficult starting point for aspectual po, on semantic grounds. That is, it would seem to be able to be ruled out as a source of Albanian $p o$, as Slavic po is generally a perfectivizing marker not an imperfectivizing one. Nonetheless, it is interesting to note that there are some functions for po to be found in various Slavic languages that make this possible source at least a plausible one, even if not necessarily compelling. In particular, while mainly perfectivizing, po shows some uses in various Slavic languages, including some South Slavic languages, that are imperfectivizing, or associated with imperfectivity, ${ }^{4}$ as in Russian po-kupat' 'to buy' vs. perfective kupit' or Slovene pobolévati 'keep getting sick, but not seriously' (IMPF). Moreover, there are some uses that mark duration, especially for relatively brief periods of time, a notion that can be construed as imperfective or progressive in the sense that while bounded the action is viewed as on-going even if just for short time; some examples are, again, Russian po-stojat' 'to stand a little' but

[3] See below in section [4] and especially footnote 14 regarding the question of apparent homophony between Albanian po and Slavic po.

[4] I say this since the change in the suffix may well be involved in the imperfective/perfective derivation here. 
also, more important for the Balkans, Serbian po-plakati 'to weep for a while' and po-plivati 'to swim for a while', Bulgarian po-vârvja 'go for while', and the Slovene use of po in what Greenberg $(2006,93-4)$ calls "attenuation", as in pobolévati, cited above, and posedéti 'sit for a while'. Finally, Dmitrieva $(1991,71)$ has shown that in Old Russian the preverb po combines with verbs of distributive, delimitative, and ingressive meanings, for which the semantics offer a parallel to the function proposed for Albanian aspectual/progressive po. Putting all of these together, Slavic po gains some degree of plausibility as a good source of the Albanian progressive po (and see below, section [4], for more on Slavic).

Still, these functions of Slavic po do not equate exactly with progressivity per se and in any case it is not clear how widespread they are in any South Slavic language, though as noted they are not unknown in that branch. Still, the way Newmark et al. describe Albanian po, namely marking "a momentary action in progress", with its reference to momentariness combined with some durativity, makes especially the South Slavic limited duration use of Slavic po, as in the examples cited above (poplakati/poplivati, etc.), a reasonable functional match for the Albanian.

Nonetheless, an external (borrowing) source for Albanian po as a grammatical element is far from a compelling etymology, given that most Slavic elements in Albanian are lexical in nature, ${ }^{5}$ so that one has to consider also possible Albanianinternal sources. Here it can be mentioned that aspectual po has often been connected by scholars to the affirmative particle use, namely the word for 'yes'. This connection is suggested by the listing in Mann $(1932,192)$ and the more comprehensive one in Newmark (1998), given above in (6), where all po's are under one entry. It is also the case that Newmark et al. $(1982,36,66)$ repeatedly refer to po as an "emphatic" element, presumably by way of linking it to the affirmative semantics of po 'yes, indeed; exactly'. Moreover, this connection is stated overtly in Orel (1998, 337, s.v. po): "The same adverb [affirmative po] is used as a particle of progressive forms". This connection does require a fairly significant semantic and functional shift, but before that is taken up, it is worthwhile considering what the source of affirmative po is.

As it happens, somewhat frustratingly perhaps but not unexpectedly when one is dealing with etymology, the origins of the affirmative use of po are not entirely clear. Several possibilities have come up over the years. Meyer $(1891,346)$, for instance, links it to the adversative element por 'but', a use found for po itself as well (see (6c) above). Orel $(1998,337)$, following Meyer, says that the formal issue standing in the way of this connection, namely the loss of word-final $-r$, is explainable "by the permanent unstressed position of the conjunction", and ultimately takes this Albanian conjunction to be a borrowing from Latin porrō 'then; moreover; but'. Camarda (1864, I:314) offered a different view, comparing po(r) with Sanskrit apara

[5] Though see section [4] below for a contact-based account of po involving Slavic. 
'later; posterior', but this connection seems somewhat forced on the semantic side and has not met with much approval.

The important thing to note, however, is that even if any of these suggestions are right, they do not really get one any closer to an understanding of the origins of aspectual/progressive po. As a result, it might be better to look to the affirmative sense in and of itself.

In this regard, Eric Hamp has made an important suggestion. ${ }^{6}$ In particular, he has suggested that affirmative po is from an original asseverative marker ${ }^{*} \overline{p e s t}$ (via the regular loss of a word-final consonant cluster and the regular development of Indo-European * $\bar{e}$ into Albanian o), which itself derives from PIE *pe (as in Latin quippe (<*quid-pe) "why so?; of course ${ }^{\text {77 }}$ ) combined with *est, an apparent 3SG injunctive mood form of 'be'. Literally, therefore, in this account affirmative po was originally "it is thus" (or the like). ${ }^{8}$

This account gives affirmative po an important Indo-European grounding in categories and formations likely to have been inherited into Albanian from PIE, even if combined innovatively within Albanian, and moreover takes this function of po as primary. In any case, though, going from either emphatic (as Newmark calls affirmative po) or originally asseverative po to a grammatical element marking "a momentary action in progress" requires some motivation, some connection between emphasis or affirmation and progressivity. The link may simply be that affirmation focuses (or can focus) on the here and now, on the present (i.e. "it is so at this very moment"); keeping in mind that the present is an always-moving target as one sec-

[6] This suggestion has a somewhat strange history of its own. In October of 1983, while I was attending a meeting of the American Association for the Advancement of Slavic Studies (AAASS) in Kansas City, in the course of a conversation Eric Hamp was having with Ronelle Alexander of the University of California, Berkeley, that I was privileged to be in on, I distinctly remember him offering the etymology I mention here for affirmative po (and can even see him in my mind's eye writing on a blackboard in the meeting room we were in as he was talking about it). In the years since then, this idea was never published, and when I once asked Eric about it, he did not remember ever having said such a thing, though he admitted that it could well be right. I know that I certainly did not make that up myself, since in 1983 I did not know enough about Albanian to be able to advance such an etymology. Thus I am happy to be able to put Eric's idea forward here and to acknowledge my debt to him for it (and for so much else that I have learned about Albanian over my many years of knowing him).

[7] Although Latin - pe by itself may seem like slim evidence for a PIE form, even with the usual comparison with Lithuanian kaĩp 'how?', there is now the further evidence of Anatolian forms such as Cuneiform Luvian/Hieroglyphic Luvian pa-/-ppa to corroborate the PIE reconstruction. See De Vaan $(2008,452-3)$ for details.

[8] A few comments are in order at this point, and I thank one anonymous reviewer for suggesting these necessary clarifications. First, it is likely (see Praust 2003) that PIE did not have an injunctive of 'be' (injunctive function for that verb being filled by nominal sentences with no overt verb). Thus the *est referred to here may not have been a PIE form per se, but rather represents an Albanian creation (possibly even an imperfect formation) that was based on the PIE injunctive category (with past tense endings and no indicative past tense prefix (the "augment")), along the lines of the development of the Albanian verbal system outlined by Klingenschmitt (2004, 225ff.) (who comments, p. 229, on the "ursprüngliche Existenz einer 3. Sg. *ie [for Albanian] < Impf. *es-t") and Matzinger $(2006,124)$. Second, although a preform *est looks like a suitable starting point for the Tosk 3SG është / Geg âsht 'is', this rather is from a prefixed form *en-esti, as argued by Hamp (1980). 
ond slips into the next and into the next and so on, the focus is thus on something that is on-going, exactly as progressive po does. Originally, therefore, po may have been calling attention to something going on before one's very eyes, something true in that sense. ${ }^{9}$

As a typological parallel to this view of the development of po, one can compare English just, which, like one sense of po (see (6a)), can mean 'exactly, precisely', as in The chef added just the right amount of salt, and which, often joined with now, occurs with progressives to refer essentially to "a momentary action in progress", as in I am just (now) stepping off of the plane. It is interesting that there are uses of just now in some varieties of English that border on grammatical use as an aspectual for progressives. As Hock \& Joseph $(2009,356)$ note, examples like (7) occur in Indian English:

\section{I am just now going home}

and although "the use of just now... at this point is not obligatory, we find here the makings of a complete and systematic shift in the formation of the present-tense system", with constructions like (7) corresponding to British English progressives, while those without just now correspond to the simple present tense:
Indian English vs. British English
I am knowing this vs. I know this
I am going to school vs. I go to school
I am just now going home vs. I am going home

The emergence of an aspectually progressive sense from po, therefore, could have involved a similar sort of shift. ${ }^{10}$

Still, more is involved here, since in the (standard) English just parallel, the independent adverbial quality of just is retained; note for instance that it can occur elsewhere in the sentence, as in Ijust am stepping off the plane (now)/Just now I am step-

[9] The connection of 'be' with 'truth' in Indo-European is perhaps worth remembering here; as discussed most thoroughly in Watkins $1967,1970,1987, \mathrm{PIE}^{*} \mathrm{H}_{1} e s$ - 'be' figures in various forms in Indo-European legal language where the meanings are tied to matters of truth and evidence (in a legal sense) more generally; as Joseph 2003, in his summary of Watkins's work, puts it: “Especially relevant here are Skt. satya- 'true; truth', Lat. sons 'guilty', OIc. sannr 'true; guilty', Hitt. asan '(it) is (so)' (in public confession). One can speculate that such derivatives might indicate that 'be', at least in a legal context, could mean 'must be' or 'be evident', with 'truth' as one side of what the evidence shows things to be and 'guilty' as the other (cf. Benveniste 1960 on PIE 'be' as originally 'really, actually be, exist')".

[10] It must be admitted, however, that the labels that are conventionally used here may be inadequate for the job at hand. Even though "progressive" is, and has been, used for po (witness Newmark et al's reference to action "in progress"), the momentaneous sense evident in the description of po in Newmark et al. is somewhat at odds with progressivity. In more traditional aspectual terms, is this imperfective, referring to an on-going action, or perfective, referring to a particular limited point? Some of the traditional distinctions may reflect a dichotomy that is too grossly demarcated. The same concern could be raised, of course, for Slavic, with regard to verbs that Dickey $(2007,331)$ refers to as "perfective verbs prefixed in po- that express the indefinite (usually brief) duration of an action". 
ping off ...) whereas Albanian po seems really to be a grammatical part of the verbal complex. Moreover, one has to wonder about the prosody, since (presumably) emphatic/affirmative po would be accentually prominent, yet such is not the case with the progressive marker (whereas English just retains its accentual properties in this "momentary action in progress" use).

\section{[4] PO IN ITS (FULLER) BALKAN CONTEXT}

The etymological speculations discussed in the previous section are admittedly a bit inconclusive, so that we cannot fully understand how po developed or from what source. Still, the important matter of why it developed in the first place and moreover why it developed in the way that it did can receive some illumination when language contact and the interactions Albanian may have had with neighboring languages are taken into account.

As to why it developed as it did, one possible explanation is that what might be called "Balkan typology" can be invoked. That is, it is reasonable to assume that once an aspectual marker like po were to arise in Albanian, its exclusively preverbal placement is explainable by reference to the prevailing typology of the operators especially, tense and mood, though even voice, if the Albanian past tense nonactive marker $\mathrm{u}$ (as in u lodha 'I got tired') is added into the mix - that occur in the verbal complex more generally. In particular, given the predominantly prefixing structure in Albanian, as elsewhere in the Balkans, as shown in (4) and (5) above, one would naturally expect a new operator, a form of aspectual modification of the verb, to likewise occur preverbally.

Alternatively, as a non-Balkan account, one can note first that in addition to productive and presumably relatively new preverbs in Albanian, such as the reversative $z h$ - as in zhdukem 'disappear' (vs. dukem 'appear'), there are some apparently old preverbs embedded in what otherwise appear to be primary verbs. For instance, marr 'take' seems to reflect *me-Hr-n-, where me- must be a preverb, attached to the root ${ }^{*} H(e) r$-, as found in Greek ó $\rho v v \mu \alpha 1$ 'take', and the *-n- reflects the Indo-European ${ }^{*}$-n- presential suffix, as seen in the $-n u$ - of the Greek form. ${ }^{11}$ If the use of such preverbs in proto-Albanian had a perfectivizing value, as they could for instance in Proto-Slavic, and as possibly also in Gothic, ${ }^{12}$ the preverbal placement of aspectual po would be consistent with inherited typology for the marking of modifying verbal categories.

With regard to the question of why such an aspectual marker should have developed at all in Albanian, language contact offers an important perspective on the

[11] The ${ }^{*}-n$ - combines with the preceding $-r$ - to give the $-r r$ - in the present, whereas in the past tense, where the presential ${ }^{*}-n$ - would necessarily be absent, the form is mora 'took', with, expectedly, a single - $r$-.

[12] If so, this could be construed as a feature that allies Albanian with other Northern European Indo-European languages; Hamp has argued, for instance, that the Winter's Law lengthening of vowels before voiced stops found in Balto-Slavic can be seen in some Albanian developments too. 
emergence of overt marking for progressive aspect. In particular, there are numerous facts from neighboring languages that seem to be highly relevant.

First, in Macedonian, although the language has been working from a more highly developed overall aspectual system (in South Slavic more generally if not already in Common Slavic) as a starting point, one finds the secondary imperfectivizing suffix -uva-, from Proto-Slavic *-ova-, occurring to a greater degree than in other Slavic languages (and especially more so than in Bulgarian). All Slavic languages have a reflex of this Proto-Slavic suffix, but colloquial Macedonian has generalized its use considerably, going beyond what is recognized as appropriate even in the standard language. ${ }^{13}$

Second, Greek has always, starting at least in Ancient Greek, had a distinction between imperfective (presential) and perfective (aoristic), a distinction that is generally encoded by different stems (e.g. Present/Imperfective in $-\imath \zeta$-vs. Aorist/Perfective in - $1 \sigma-)$. In the Middle Greek period there was much reshaping of the marking of the different stems (Horrocks 1997, 233-46), usually by reuse (that is, the spread, with some reanalysis) of an Ancient Greek suffix. One fairly productive overt mark that arose innovatively (partly an adaptation of the earlier - vv- present suffix) for imperfective aspect on many verbs was the suffix $-n-$. This suffix generally imperfectivized an aorist stem, and was deployed in what Horrocks $(1997,235)$ calls "the new principle of substituting imperfective [-n-] for aorist [-s-]". Some examples, which in some instances involved the reshaping of the imperfective part of an Ancient Greek (AGk) opposition of characterized present vs. differently characterized aorist, include the following:

(9) li-n-o 'loose' (vs. perfective (aoristic) stem li-s-) [AGk $\lambda v-/ \lambda v-\sigma-]$

Jilo- $n-$ 'declare' (vs. perfective (aoristic) stem ðilo-s-) [AGk $\delta \eta \lambda \mathrm{o}-/ \delta \eta \lambda \omega-\sigma-]$ $s v i-n$ - 'extinguish' (vs. perfective (aoristic) stem svi-s-) [AGk $\sigma \beta \varepsilon v v v-/ \sigma \beta \varepsilon-\sigma-]$ fer-n- 'bear' (imperf. variant of once bi-aspectual fer-) [AGk $\varphi \varepsilon \rho-/ \varepsilon \dot{\varepsilon} v \varepsilon \gamma$-] stel-n- 'send' (vs. perfective (aoristic) stil-) [AGk $\sigma \tau \varepsilon \lambda \lambda-/ \sigma \tau \varepsilon \imath \lambda-]$ ðix-n- 'show' (vs. perfective (aoristic) ðik-s-) [AGk $\delta \varepsilon 1 k-v v-/ \delta \varepsilon 1 k-\sigma-(\delta \varepsilon l \xi-)]$

However, this marking is not consistent for all verbs, in that many presents lack the -n-, e.g. yraf-o 'I write, I am writing', or enter into other marking schemes, as with -iz-/-is-. Still, the upshot is that imperfective aspect has a far more consistent overt mark in Modern Greek than it had in any earlier stages, and it is a mark that was absent earlier in many of the verbs that now have it. It is thus innovatively spreading, and has been for some time.

Third, within post-Classical times, Greek has extended the imperfective/perfective opposition into the future tense, since there is now a distinction between $\theta a$ yraf-o 'I will be writing' and $\theta$ a yrap-s-o 'I will write' which was not possible in Ancient

[13] Victor Friedman (personal communication). 
Greek with its monolectal and, according to Goodwin $(1875,19)$, aspectually neutral

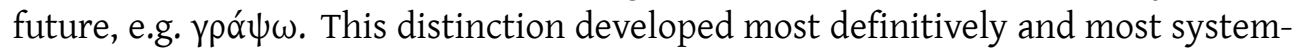
atically only with the want-based (and pan-Balkan) periphrastic future of Medieval Greek, where it is solidly entrenched and continues, as just noted, into contemporary Greek; the earlier post-Classical future periphrasis with have ( $\left.{ }^{\prime} \chi \omega\right)$ did not allow for imperfective/perfective differentiation, and though such a distinction has been claimed (e.g. by Jannaris 1897, 443-4 for the other post-Classical future-referring periphrasis, the construction with $\mu \varepsilon \dot{\varepsilon} \lambda \lambda \omega$ 'be about to'), Markopoulos $(2009,30-33)$ has demonstrated that such is not the case.

If we take progressivity to be one of the dimensions of imperfectivity, as in Comrie (1976), where imperfective is broken down into habitual and continuous, and continuous into nonprogressive and progressive, these three sets of facts mean that in the multi-lingual Balkan context in which Albanian (and the other Balkan languages) existed in the Medieval period, not only was imperfectivity overtly marked in some languages but also that overt marking was spreading. The emergence of a means of signaling one type of imperfectivity in a language that did not otherwise have an overt means of marking aspect can surely happen independently, but the coincidence of relevant developments in adjacent languages might be considered to be difficult to ignore; thus, external influence could well have played a role, though perhaps just a facilitating one, helping along an internally originating process.

What this last possibility would mean in terms of how the development of po was implemented is that either Albanians exposed to Greek or Balkan Slavic imported a foreign category into their verbal system, or else Greeks or Balkan Slavs learning Albanian imposed their aspectual category onto their Albanian. But it must be asked why in each case po would be selected if it were not already showing signs of such use in Albanian. That is, it is hard to see what the basis would be for innovating an aspectual use for, say, affirmative po, if it could not already be used in that way. Thus, it would appear that the best interpretation of what happened is that in this case, contact between Albanian speakers and speakers of other languages in the Balkans helped along an already-emerging native process, a scenario which has been argued, e.g. by Friedman (2003), to be operative in the emergence of marking for evidentiality in the Balkans (where Turkish was the catalyst).

Balkan Slavic might actually be the more suitable catalytic agent in this case, in the light of the perfective but (brief) durational preverb po- found (see section 3) in Serbian and elsewhere in South Slavic. Moreover, while aspectual/progressive po is found (as noted above) in both Tosk and Geg Albanian, it is missing from the peripheral Tosk dialects, in particular Arvanitika and Arbëresh, and this distribution is consistent with taking Slavic to be a catalyst, inasmuch as Slavic influence on Albanian was weakest in those outlying dialect areas. And, the presumably rela- 
tively recent homophony between Slavic po- and Albanian $p o^{14}$ is exactly the sort of chance occurrence that can have significance in language contact situations. Janse (2009) has argued for such an effect in certain uses of the Cappadocian Greek 1Pl person-marking ending -misti based on the formal similarity with Turkish temporal marking (past tense) suffixes - mIş-tI, and he points to similar sorts of effects in other language contact situations. ${ }^{15}$

\section{[5] CONCLUSION}

From the perspective of Proto-Indo-European, it is particularly interesting that Albanian has innovatively developed an overt marking for a new category associated with imperfectivity, where there apparently was no such marking and perhaps even no such category in the system previously. ${ }^{16}$ Proto-Indo-European is generally reconstructed ${ }^{17}$ with an aspectual system, but one of limited scope, showing marking for stativity (the classical "perfect" formation generally with reduplication and a special set of endings), and in the past tense, a distinction between perfective (the classical "aorist") and imperfective (the "imperfect" tense, based on the present stem). But there does not seem to be a basis for reconstructing an overt imperfective marking in present tense forms. ${ }^{18}$ The development of po in Albanian thus shows how the Indo-European system can be embellished, and more generally how aspectual categories and aspectual marking can develop and come to play an important role in the verbal system.

Moreover, from a methodological standpoint, the discussion here highlights the importance, for assessing developments in Albanian, of remembering that the language must be considered in its three "personae", that is, as a member of the set of human languages, as a Balkan language, and as an Indo-European language. All three play a role in this account, in that, as with so much in the Balkans, a combination of language typology, language history, and language contact come together

[14] Albanian o from ${ }^{*} \bar{e}$ is probably not all that old a change at least when compared with other developments in the phonology. Note that PIE * gave Albanian $a$ (as in natë 'night' $<{ }^{*}{ }^{*} k^{w} t$-) so that $o$ is somewhat new to the Albanian phonological system. And, of course, in some parts of the Slavic world, as in Russian, orthographic "po" has a lower and less rounded back vowel than the Albanian.

[15] Janse writes (p.96): "The conflation of formally, but not functionally identical elements is attested in other contact languages. Russenorsk, for instance, has one all-purpose preposition på which is clearly chosen because of the formal, but not functional, similarity between the Norwegian preposition på and the Russian preposition po (Hock 1991, 523; Winford 2003, 274). Sango has only one locational/temporal preposition, viz. nà, which has formal, but not functional, counterparts in Ngbandi and other Ubangian languages, and also in Kitúba, a Bantu-based contact language, and other Bantu languages in general (Pasch 1997, 248)."

[16] Note that in the Greek and Macedonian cases discussed in section [4] (see example (9), e.g.), what was involved was an extension of an already-existing aspectual marker, not the innovation of an altogether new category where one did not exist before. The reason for the "perhaps" regarding the category is that the duke + participle formation, if old enough, would give a basis for assuming a category indicating progressivity before the emergence of $p o$.

[17] See Fortson IV 2009, 83 for a recent summary of the conventional wisdom on aspect in Proto-Indo-European.

[18] Rather, there were various ways of making "characterized" present tense system stems, e.g. with the nasal affix noted above, but no consistent marking. 
to illuminate, even if not to fully explain, Albanian po.

\section{AC KNOWLEDGMENTS}

Several people have contributed to making this study the best it can be. I would like to thank the two anonymous reviewers for extraordinarily rich and insightful comments that improved this article considerably. So too I owe thanks to Steve Dickey and Marc Greenberg, both of the University of Kansas, for steering me onto the right course regarding the Slavic preverb po. Comments from the audience at the University of Georgia in May 2009, especially those of Paul Kiparsky, Jared Klein, and my colleague Dan Collins, were helpful too. Finally, I thank my good friend Victor Friedman for sharing his insights on Macedonian with me.

\section{REFERENCES}

Benveniste, Émile. 1960. "Être" et "avoir" dans leurs fonctions linguistiques. Bulletin de la Société de Linguistique de Paris 55. 113-134.

Camarda, Demetrio. 1864. Saggio de grammatologia comparata sulla lingua Albanese. Livorno: Successore di Egisto Vignozzi.

Comrie, Bernard. 1976. Aspect. Cambridge: Cambridge University Press.

De Vaan, Michiel. 2008. Etymological dictionary of Latin and the other Italic languages. Leiden: Brill.

Decker, Rodney J. 2007. Koine Greek Reader: Selections from the New Testament, the Septuagint, and early Christian writers. Grand Rapids: Kregel Publications.

Dickey, Stephen. 2007. A prototype account of the development of delimitative poin Russian. In D. Divijak \& A. Kochańska (eds.), Cgnitive paths into the Slavic domain, 329-374. Berlin: Mouton de Gruyter.

Dmitrieva, Olga. 1991. Formirovanie semanticheskoj struktury russkogo glagol'nogo prefiksa po-. In Aktivnye processy vjazyke i rechi, 68-74. Saratov: Izdatel'stvo Saratovskogo Pedagogicheskogo Instituta.

Fortson IV, Benjamin W. 2009. Indo-European language and culture. 2nd ed. Oxford: Blackwell Publishing.

Friedman, Victor A. 2003. Evidentiality in the Balkans with special attention to Macedonian and Albanian. In Alexandra Aikhenvald \& R. M. W. Dixon (eds.), Studies in evidentiality, 189-218. Amsterdam: John Benjamins Publishing Co.

Goodwin, W. W. 1875. Syntax of the moods and tenses of the Greek verb. New York: St Martin's Press. 
Greenberg, Marc L. 2006. A short Slovene reference grammar. Duke University/University of North Carolina, Chapel Hill: SEELRC.

Hamp, Eric. 1980. Albanian është. In Kathryn Klar, Margaret Langdon \& Shirley Silver (eds.), American Indian and Indoeuropean studies: Papers in honor of Madison S. Beeler, The Hague: Mouton.

Hock, Hans Henrich. 1991. Principles of historical linguistics. 2nd ed. Berlin: Mouton de Gruyter.

Hock, Hans Henrich \& Brian D. Joseph. 2009. Language history, language change, and language relationship. An introduction to historical and comparative linguistics. Berlin: Mouton de Gruyter 2nd edn.

Horrocks, Geoffrey. 1997. Greek. A history of the language and its speakers. London: Longman.

Jannaris, Antonius. 1897. An historical Greek grammar. London: MacMillan.

Janse, Mark. 2009. Watkins' Law and the development of agglutinative inflections in Asia Minor Greek. Journal of Greek Linguistics 9. 93-109.

Klingenschmitt, Gert. 2004. Das Albanische als Glied der indogermanischen Sprachfamilie. In Jens Rasmussen (ed.), In Honorem Holger Pedersen: Kolloquium der Indogermanischen Gesellschaft vom 26. bis 28. Marz 1993 in Kopenhagen, 221-233. Wiesbaden: L. Reichert.

Mann, Stuart. 1932. A short Albanian grammar with vocabularies, and selected passages for reading. London: D. Nutt.

Markopoulos, Theodore. 2009. The future in Greek: From Ancient to Medieval. Oxford: Oxford University Press.

Matzinger, Joachim. 2006. Der altalbanische Text Mbsuame e kreshtere (Dottrina cristiana) des Leke Matrenga von 1592. Eine Einführung in die albanische Sprachwissenschaft. Dettelbach: Röll.

Meyer, Gustav. 1891. Etymologisches Wörterbuch der albanesischen Sprache. Strassburg: K. Trübner.

Newmark, Leonard. 1998. Albanian-English dictionary. Oxford: Oxford University Press.

Newmark, Leonard, Philip Hubbard \& Peter Prifti. 1982. Standard Albanian: A reference grammar for students. Stanford: Stanford University Press. 
Orel, Vladimir. 1998. Albanian etymological dictionary. Leiden: Brill.

Pasch, Helma. 1997. Sango. In Sarah G. Thomason (ed.), Contact languages. A wider perspective, 209-270. Amsterdam: John Benjamins.

Praust, Karl. 2003. A missing link of PIE reconstruction: The injunctive of ${ }^{*} \mathrm{H}_{1}$ es'to be'. In Karlene Jones-Bley, Martin Huld, Angela Della Volpe \& Miriam Robbins Dexter (eds.), Proceedings of the Fourteenth Annual UCLA Indo-European Conference, Los Angeles, November 8-9, 2002 (Journal of Indo-European Studies Monograph Series, No. 47), 112-144. Washington, DC: Institute for the Study of Man.

Watkins, Calvert. 1967. Latin sons. In Walter W. Arndt (ed.), Studies in honor of G. S. Lane, 186-194. Chapel Hill: University of North Carolina Press.

Watkins, Calvert. 1970. Studies in Indo-European legal language and institutions and mythology. In George Cardona, Henry Hoenigswald \& Alfred Senn (eds.), IndoEuropean and Indo-Europeans, 321-354. Philadelphia: University of Pennsylvania Press.

Watkins, Calvert. 1987. 'In the interstices of procedure': Indo-European legal language and comparative law. In Wolfgang Meid (ed.), Studien zum indogermanischen Wortschatz, 305-314. Innsbruck: Innsbrucker Beiträge zur Sprachwissenschaft.

Winford, Donald. 2003. An introduction to contact linguistics. Oxford: Blackwell Publishing.

AUTHOR CONTACT INFORMATION

Brian D. Joseph

Department of Linguistics

The Ohio State University

222 Oxley Hall

Columbus, Ohio 43210-1298

USA

joseph.1@osu.edu 